
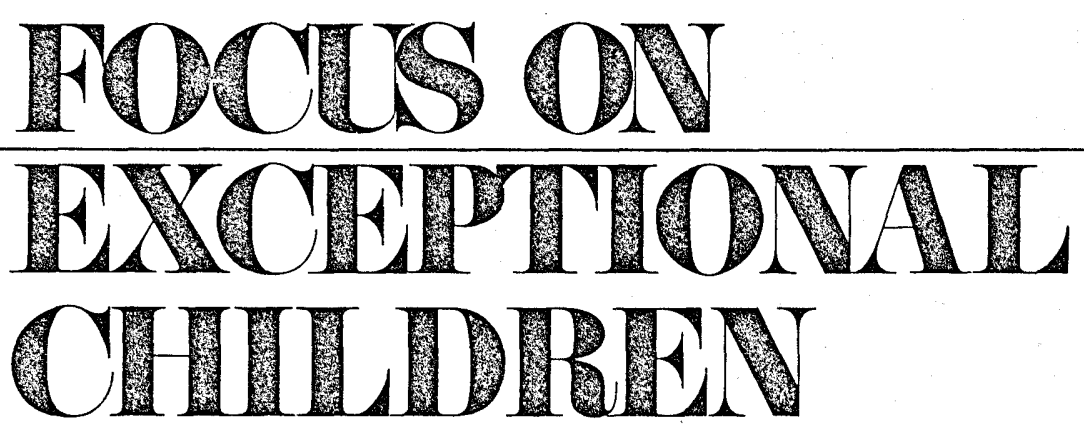

\title{
Cognitive-Behavior Modification: Application with Exceptional Students
}

Karen R. Harris

\begin{abstract}
"When I use a word," Humpty Dumpty said, "it means just what I choose it to mean - neither more nor less." "The question is," said Alice, "whether you can make words mean so many different things." "The question is," said Humpty Dumpty, "which is to be the master -that's all."
\end{abstract}

Lewis Carroll Through The Looking Glass

Interest in the application of cognitive-behavioral interventions with exceptional students is increasing among both researchers and practitioners. Cognitive-behavioral models for teaching and learning represent an integrated, eclectic approach influenced by behaviorism, social-learning theory, cognitive psychology, developmental psychology, and instructional theory (Craighead, Wilcoxon-Craighead, \& Meyers, 1978; Mahoney, 1977a). Teachers of exceptional children have received training in these areas, and many report the use of an eclectic approach - choosing and combining what appears to be the best from diverse sources. Kendall and Hollon (1979), however, have noted the dangers of unguided, unselective eclecticism and the need for empirical support. Research on a variety of cognitive-behavioral interventions, collectively labeled cognitive-behavior modification (CBM), helps to provide both the guidance and empirical support needed.

\section{ORIGINS, DEVELOPMENT, AND DEFINITION}

The origins and development of CBM present a complex picture. Trends in the field of behavior modification, including development of social-learning theory and research on self-regulation, are discussed first. Contributions from the areas of cognitive psychology, private speech, and instruction are then noted.

\section{Behavior Modification}

Behaviorists have traditionally explained human behavior through environmental antecedents and consequences, limiting research and procedures to readily observable

Karen Harris is an Assistant Professor of Special Education, University of Maryland. 
and measurable overt behaviors. The focus of behavior modification is on establishing a behavior, increasing or maintaining a behavior, or reducing or eliminating a behavior (Mahoney \& Thoresen, 1974). Maladaptive behaviors are identified, and incompatible, adaptive behaviors are taught. The assumption underlying the behavioral approach is that "the best way to change thoughts and feelings is to change behavior directly; changes in thoughts and feelings will then follow" (Ledwidge, 1978, p. 371). To the radical behaviorist, cognitions have no place in the science of behavior. Although more moderate behaviorists do not deny the existence of the mind, cognitive components of behavior change are considered either irrelevant or trivial (Kendall \& Hollon, 1979; Ledwidge, 1978).

Sabatino, Miller, \& Schmidt (1981) noted that behavior modification procedures with exceptional students have helped to increase academic response rates, talking, instruction following, positive prosocial interactions, attendance, achievement, and grades. Behavior modification procedures have also helped to establish the importance of a performance orientation, methodological rigor, empirical evaluation, and observable behavioral change (Kendall \& Hollon, 1979; Mahoney \& Thoresen, 1974).

Nonetheless, there has been a growing dissatisfaction with traditional behavioral interventions over the years. Part of this dissatisfaction arose from the limited scope and effectiveness of behavioral interventions, which used discrete procedures to change certain restricted behaviors (Kendall \& Hollon, 1979; Mahoney, 1977a, 1977b) and part arose from frequent failure to obtain durable and

FOCUS ON EXCEPTIONAL CHILDREN (ISSN 0015-511X) (USPS 203-360) is published monthly except June, July, and August as a service to teachers, special educators, curriculum specialists, administrators, and those concerned with the special education of exceptional children. This journal is abstracted and indexed in Exceptional Child Education Resources, and is also a vailable in microform from Xerox University Microfilms, Ann Arbor, Michigan. Subscription rates, $\$ 15.00$ per year. Copyright 1982, Love Publishing Company. All rights reserved. Reproduction in whole or part without written permission is prohibited. Printed in the United States of America. Second class postage is paid at Denver, Colorado. POSTMASTER: Send address changes to:

\footnotetext{
Love Publishing Company

Executive and Editorial Office

1777 South Bellaire Street

Denver, Colorado 80222

Telephone (303) 757-2579
}

\section{EDITORIAL BOARD}

Edward L. Meyen

University of Kansas

Richard J. Whelan

University of Kansas Medical Center

Stanley F. Love Publisher generalizable effects after treatment (Abikoff, 1979). This dissatisfaction is evident within the field of special education. Based on their work with hyperactive children, Douglas and her colleagues (Douglas, 1975; Douglas, Parry, Marton, \& Garson, 1976) have suggested that relying solely on operant techniques in developing interventions is unwise, as long-term effects and resistance to extinction have not been established.

In addition, the use of reinforcement may result in unique responses among hyperactive children - disrupting their performance, decreasing their attention to the task, and increasing impulsivity. The use of task-extrinsic rewards, especially to motivate learning, may have widespread undesirable effects (cf. Meichenbaum, 1979a). Sabatino et al. (1981) noted that emphasizing behavior modification procedures may preclude exceptional children from learning how to learn, and that special education has become overdependent on intervention strategies unrelated to cognitive development.

Concurrent with the growing dissatisfaction with traditional behavior modification techniques, the behavioristic model has gradually expanded (Kanfer \& Karoly, 1972). Behavior modification has "gone cognitive." The view that behavior modification involves cognitive processes, and that cognitive factors are involved in the learning process (Craighead et al., 1978) has slowly been accepted and integrated into behavioral interventions. This movement was expressed in the following statement:

\footnotetext{
The predominant conceptualization of the "Behavior Therapies" as conditioning techniques involving little or no cognitive influence on behavior change is questioned. It is suggested that current procedures should be modified and new procedures developed to capitalize upon the human organism's unique capacity for cognitive control. (Goldfried, cited in Kendall \& Hollon, 1979, p. 7)
}

Some of the new ingredients that have found their way into behavior modification include the use of self-reports for assessment and treatment, attempts to alter thinking, imagery, and attitudes, and an emphasis on involving individuals in their own treatment (Kanfer \& Phillips, 1970; Ledwidge, 1978).

\section{Social-Learning Theory}

Covert, or internal, processes are viewed among sociallearning theorists as crucial elements in understanding human behavior (Thoresen, 1974). Environmental antecedents and consequences are seen as mediated by cognitions such as internal dialogue, perceptions, and beliefs (Craighead et al., 1978). Moreover, cognitions, or the "internal environment," may act as antecedents and consequences (Mahoney \& Thoresen, 1974). Bandura (1978) advanced the concept of reciprocal determinism - that environmental, person, or behavioral variables may act on, and interact with, one another over time. He 
also demonstrated the importance of self-efficacy and the role of modeling in learning and development (Bandura, 1977a, 1977b). Modeling has become an integral part of many CBM procedures (Denney, 1973; Harris, 1980, 1981a; Harris \& Brown, 1982).

Mahoney (1977a) listed several factors that sociallearning theory indicates are relevant to the modification of cognition, including: motivation and incentives, demand characteristics, performance and outcome expectancies, a rationale for performance, graduated performance tasks, adequate and relevant perceptual focusing, optimal information processing, and the individual's biological state. Consideration for these variables has been incorporated into various CBM procedures, and researchers have begun to evaluate their individual importance and effectiveness (Harris, 1981b; Keogh \& Glover, 1980; Meichenbaum, 1980).

\section{Self-Regulation}

Behavioristic research on the development of selfcontrol and the process of self-regulation has also been a major contributor to the development of CBM procedures (researchers have also investigated self-control from a cognitive perspective - cf. Pressley, 1979). Craighead et al. (1978) described self-regulation as a general cognitive strategy, in which the child or adult determines a criterion and then observes his/her own performance, compares the two, and appropriately self-reinforces or self-punishes. Cognitive processes and individual characteristics such as motivation level and learning history are intricately involved in the process of self-regulation. The development of self-regulation is seen as a gradual process in which the child takes over the communicative and regulative responsibilities formerly assumed by the adult (Wertsch, 1979a, 1979b). Calling it a "behavioristic excursion into the lion's den," Kanfer and Karoly (1972) developed a model of self-regulation that includes three basic steps: self-monitoring, self-evaluation, and selfreinforcement.

\section{Cognitive Psychology}

Cognitive psychology and interventions, as opposed to behavioral interventions, begin with the view that behavior is influenced by unobservable, and sometimes unconscious, covert operations. Training regimens and interventions are aimed at cognitions, including private speech, thoughts, imagery, perceptions, beliefs, expectancies, and attributions (cf. Harris, 1981a; Kendall \& Hollon, 1979; Meichenbaum, 1977). Cognitive therapists believe that "the critical determinants of human behavior lie within the individual" (Mahoney, 1977a, p. 6). Although environmental events are seen as important, they are not of primary importance (Meichenbaum, 1977, 1980b). Most cognitive interventions focus on systematically replacing nonfunctional, inappropriate cognitions with effective, organized, and task (or situation) relevant cognitions and behaviors.

Cognitive interventions, however, often incorporate behavioral components. Cognitive therapists view cognitions as behaviors, subject to the same laws of development, modification, and extinction as overt behaviors. Therefore, cognitive training procedures frequently apply operant principles (e.g., shaping, positive reinforcement, response cost, elimination of eliciting cues, extinction, controlled practice, and arranging for a high percentage of correct responses) to covert behaviors, including private speech and imagining. Cognitive therapists may also manipulate environmental factors and events in order to affect cognitions (Craighead et al., 1978; Pressley, 1979). In fact, determining where cognitive training ends and CBM begins is sometimes difficult. Keogh and Glover (1980) noted that differentiating between CBM and cognitive training may be unnecessary from a practical standpoint.

Although the behavioral and cognitive viewpoints at first appeared to be fundamentally incompatible, and have resulted in antagonism and bitter dispute (Mahoney, 1977a), they actually share several similarities. Both cognitive and behavioral interventions are "ahistorical" in that they do not focus on traditional, semantic therapy constructs such as the unconscious, infantile sexuality, and so on (Hollon \& Kendall, 1979; Ledwidge, 1978). Both viewpoints emphasize a structured approach, methodological rigor, and empirical support.

\section{Private Speech: A Cognitive-Developmental Perspective}

Postulated relationships between private speech, thought, and behavior have also been an influential force in the development of CBM procedures and on the application of CBM with exceptional children. Private speech refers to speech that is directed to the self, ". . . not intended for, or not effectively adapted for, communication with others" (Zivin, 1979, p. 9). Private speech is self-regulating, may be either overt (out loud) or covert (internal), and may operate on motor activity, cognitive processing, or perceptual processing.

Soviet researchers were the first to explore the cognitive-developmental functions of private speech. Vygotsky 1934/1962) saw private speech as serving the cognitive functions of orienting, organizing, and structuring behavior. He believed that children used private speech to consciously understand or focus on a problem or situation and to overcome difficulties. Based on his research, Vygotsky reported that overt private speech increases until the age of 6 or 7, declining and becoming primarily covert by age 8 to 10 . As private speech becomes covert, changes occur in its semantic, structural, and grammatic 
form. Covert private speech is seen as one step removed from thought, where, in Vygotsky's terms, "Words die as they bring forth thought" (p. 149). Individuals at any age, however, may resort to "thinking out loud" when faced with a difficult problem or situation (Zivin, 1979).

Luria $(1960,1961 \mathrm{a}, 1961 \mathrm{~b})$ demonstrated three stages in the development of verbal self-regulation. In the first stage (age $11 / 2-21 / 2$ ), the speech of others controls and directs the child's behavior to some extent, while the child's own speech is ineffective in controlling his/her behavior. The child's overt private speech can initiate behavior to some extent in the second stage (age 3-4), but cannot inhibit behavior. During the third stage $(41 / 2-$ $51 / 2$ ), the child's private speech, overt or covert, is able to initiate, direct, and inhibit behavior. Luria believed that language regulated behavior through neurophysiological relationships, and hypothesized that language could help to develop, modify, or maintain behaviors among individuals with developmental or behavioral problems. His research with children having a syndrome similar to hyperactivity supported this hypothesis (Luria, 1961a).

Western researchers have investigated the occurrence of spontaneous verbalizations and strategies, and their ability to mediate behavior, under the labels "mediational deficiency" and "production deficiency" (Kendler, Kendler, \& Wells, 1960; Kuenne, 1946; Maccoby, 1964; Reese, 1962). Flavell and his colleagues (Flavell, Beach, \& Chinsky, 1966; Keeney, Cannizzo, \& Flavell, 1967) explained production deficiency as a failure to produce task relevant verbalizations and/or strategies. They found that production deficiencies occur among students who have the intellectual capabilities, components, and strategies required for a task. Mediational deficiencies occur when verbalizations and strategies are produced but fail to affect behavior.

The way in which private speech and self-regulation work together can be clarified by an example. Consider the private speech that may occur while a teacher prepares a lesson. The hypothetical teacher is experienced, and gets the material needed to plan the lesson almost automatically. With little or no private speech (overt or covert), the teacher gets the plan book, related books, and materials, then gets situated in the best work environment, with adequate lighting, several pencils, and minimal distractions. In becoming involved in the work, the teacher engages in several cognitive processes, including private speech, self-regulation, imagining, and anticipating. The internal dialogue runs something like this: "What do I need in order for them to understand?" "They should be able to ..." "I'll try ..." "Last year ...." "I can use...."

When a problem is encountered, the teacher begins to think more in full sentences, asking: "How am I going to get this across?" After beginning to work out an idea, the teacher mutters out loud, "No, no, that isn't going to work." Evaluating the plan and imagining the students' reactions, the teacher thinks, "This is too hard, l've got to break it down into smaller steps." In working out the problem, self-evaluation and self-reinforcement messages include, "I've got it" ... "This is going to be a good lesson." Upon reaching a point at which the teacher would really rather be doing something else, coping messages enable staying on task: "If I get this done, I can later relax and won't have to worry about it." The teacher found that this thought is usually effective.

Although private speech has rarely been directly investigated among exceptional students, Harris $(1981 \mathrm{lb}, 1982)$ found that young learning disabled children working on a problem-solving task produced significantly more taskirrelevant private speech (word play, descriptions of irrelevant stimuli, general and affective statements) than normally achieving children, and very little task-relevant private speech. After CBM training, this pattern was reversed; task performance and persistence significantly increased.

\section{Instructional Theory and Research}

Instructional research offers valuable contributions to the construction of CBM procedures for use with children in classroom settings. Tobias (1982) noted that time on task alone is not enough for learning; how the student uses that time and what the student is thinking while working are important variables. Students with low prior achievement need a good deal of instructional support and stimulation, and may need assistance in improving cognitive processing of instruction. Research indicates that learning is facilitated when the learner is active and involved (Henker, Whalen \& Hinshaw, 1980); when the task requires understanding, meaningful processing, and the development of cognitive representations of new behaviors rather than task-specific response sets (Anderson, 1970; Denney, 1975); and when a demonstration-prompt-practice format and sufficient practice are provided (Stevens \& Rosenshine, 1981).

Analyses of both the task and the learner, as well as teacher direction, an academic focus, and individualization are also characteristic of effective instruction (Case, 1978; Stevens \& Rosenshine, 1981). In addition, researchers are increasingly indicating that teaching exceptional students how to think is at least as important as teaching them what to think (Borkowski \& Cavanaugh, 1979; Deshler, Alley, Warner, \& Schumaker, 1981; Maier, 1980; Meichenbaum \& Asarnow, 1979). Emphasis is placed on learning to learn, on 'improving students' self-control and self-awareness of their own learning processes" (Brown, Campione, \& Day, 1981, p. 14).

Several recently developed eclectic procedures for teaching and learning combine the results of CBM and instructional research. Over the past five years a learning 
strategies model has been developed at the University of Kansas Institute for Research in Learning Disabilities (Deshler et al., 1981). And Lloyd (1980) has set forth the steps involved in applying attack strategy training to academic instruction. The University of Virginia Learning Disabilities Research Institute is evaluating training techniques that fall under the general rubric of CBM for use with impulsive and hyperactive children (Hallahan, 1978).

Brown et al. (1981) reported on techniques for enhancing learning to learn among EMR and remedial students. The "turtle technique" (Robin, Schneider, \& Dolnick, 1977; Schneider, 1974) and a "think aloud" program (Camp, Blom, Hebert, \& Van Doorninck, 1977) have been developed to teach delayed responding and social problem solving to aggressive children. Self-instructional training has been applied to a host of behavioral and academic problems among both normal and exceptional students (Meichenbaum, 1977; Meichenbaum \& Asarnow, 1979).

\section{CBM: Rationale and Definition}

Having traced the historical development of and some major contributors to the CBM perspective, one can see that CBM is based on belief in the interactive, reciprocal nature of cognitions, feelings, and behaviors. Though cognitive, affective, and behavioral viewpoints are each necessary for an understanding of human behavior and the development of interventions, none alone is sufficient (Craighead et al., 1978; Kendall \& Finch, 1979; Mahoney, 1977a). Thus, a purposeful, integrated intervention approach should prove superior when children face significant difficulties (Kendall \& Hollon, 1979). Although further validation is needed, evidence supporting this tenet is increasing (Hollon \& Kendall, 1979). Furthermore, CBM emphasizes the active role children play in their own development and learning, rather than "reshaping" controlled by the teacher (Henker et al., 1980). Deficits are addressed, but the focus is on desired skills and behaviors, developmental capabilities, and ultimately placing the child in control (McKinney \& Haskins, 1980; O'Leary, 1980).

The widespread interest in cognitive-behavioral interventions has led to a variety of methods and labels. The eclectic nature of the approach prompted Craighead et al. (1978) to use the phrase "cognitive-social-developmental behavioral approach to child-clinical intervention" (p. 161); they noted that this approach has generally been labeled CBM. CBM is a generic term, encompassing numerous procedures and formats based on a common rationale and goals (Hollon \& Kendall, 1979; Kendall, 1977; Keogh \& Glover, 1980; Mahoney, 1977a, 1977b; Meichenbaum, 1977, 1979b). The terms CBM, general strategy training, and self-instructional training (among others) are frequently used synonymously. Actually, general strategy training and self-instructional training are procedures that fall under the CBM umbrella; they are sometimes used alone and are often incorporated into more complex training regimens.

$\mathrm{CBM}$ training regimens number almost as many as researchers and practitioners working within the CBM philosophy. Meichenbaum (1979a) has noted that the content and format of CBM training regimens can be thought of as falling along continua from concrete to abstract, and from directive to generally didactic teaching. The picture is not likely to get any clearer, as CBM is a dynamic field. New and coming contributors to CBM interventions include metacognition; information processing; attribution theory; research on perception, attention, and memory; expectancy formation; and existential-gestalt psychology (Hollon \& Kendall, 1979; Mahoney, 1977a; Meichenbaum, 1979a). Kendall and Hollon (1979) noted that this multidimensional process should be encouraged and stated that, "It may be somewhat premature to go any further in attempting to categorize the approach, to define its components, or to outline its methods" (p. 3).

Therefore, a flexible definition is needed. The term CBM is used in this article to refer to the selective, purposeful combination of principles and procedures from diverse areas into training regimens or interventions, the purpose of which is to instate, modify, or extinguish cognitions, feelings, and/or behaviors. The principles and procedures chosen may be either partially or fully integrated; cognitive and/or behavioral techniques may be directed at any combination of cognitive and/or behavioral targets (Hollon \& Kendall, 1979). Whether the procedures and targets are cognitive, affective, or behavioral should depend on characteristics of the problem, the individuals involved and the setting. These decisions, however, often seem to depend on the allegiance(s) of the designer.

CBM may be particularly appropriate for exceptional students, as they exhibit characteristics such as learned helplessness, an external locus of control, production and mediation deficiencies, and deficits in inhibition, self-regulation, problem solving, and means-ends thinking (cf. Brown, 1974; Brown et al., 1981; Denney \& Turner, 1979; Havertape \& Kass, 1978; Kendall \& Finch, 1979; Reid \& Hresko, 1980). Exceptional students may not make use of verbal mediation processes or may not have developed an effective linguistic control system (Camp, 1977; Craighead et al., 1978; Meichenbaum, 1976). Classroom procedures can be readily modified to include CBM approaches (Deshler et al., 1981; Meichenbaum \& Asarnow, 1979), and CBM can be tailored to individuals of all ages (Meichenbaum, 1980a). The use of some CBM procedures, however, may be inappropriate with severely and profoundly retarded individuals, and 
some students may need careful pretraining in prerequisite skills and CBM components (Kendall, 1977).

\section{COMPONENTS, PROCEDURES, AND APPLICATIONS}

Although CBM regimens vary, several typical components have been identified (Abikoff, 1979; Lloyd, 1980). Students learn to control their own behavior through processes such as self-instruction, self-monitoring, self-assessment, and self-reinforcement. Verbalizations, often overt at first and later covert, are used to guide the student through a series of task-analytic steps aimed at producing effective behavior. Modeling is a common and effective method of teaching the learner to verbalize through these steps. Additionally, many cognitive procedures incorporate teaching students to delay responding in order to evaluate various alternatives.

Some research comparing various components has been done (cf. Denney \& Turner, 1979; Keogh \& Glover, 1980; Meichenbaum \& J. Goodman, 1971; O'Leary, 1980), but further study of the relative effects of singular or combined components is needed. Recent reviews of research in this area have indicated that programs using abbreviated steps or differing components can significantly affect behavior (Abikoff, 1979; Finch \& Spirito, 1980; Meichenbaum, 1979a).

Two CBM regimens, sometimes used alone and of ten incorporated into other regimens are illustrated in this section. The first is Meichenbaum's self-instructional training regimen. Meichenbaum has been credited with providing the major rationale underlying CBM (Abikoff, 1979), though Ledwidge (1978) viewed self-instructional training as a descendant of Rational-Emotive Therapy (Ellis, 1963). Problem-solving training is then discussed.

\section{Self-Instructional Training}

Self-instructional training is a particularly relevant method of developing verbaly mediated self-control. It has been noted as one of the most promising CBM approaches for use with children (Kendall, 1977). Reent reviews credit self-instructional training as demonstrating the most promising results with attentional problems and with the development of nonimpulsive behavior (Craighead et al., 1978; Kendall \& Finch, 1979). Selfinstructional training is also seen as an especially viable intervention to alleviate learned helplessness, develop self-esteem, and improve maintenance of treatment effects (Borkowski \& Cavanaugh, 1979; Canino, 1981).

The behavioral components of self-instructional training include modeling, successive approximations, graduated difficulty, prompts, feedback, and social reinforcement. Self-regulation is stressed, and students are trained explicitly in the use of task-relevant private speech and the inhibition of task-irrelevant private speech. The natural development of private speech is used as a guide; control over behavior is gradually faded from overt verbalizations by an adult to covert verbalizations by the student. Training is built around four basic steps (Meichenbaum \& S. Goodman, 1979):

1. Cognitive modeling: The adult model performs a task while talking aloud; the child observes.

2. Overt guidance: The child performs the task using the same verbalizations, assisted by the adult at first, then alone.

3. Faded self-guidance: The child whispers the instructions (often in an abbreviated form) while going through the task.

4. Covert self-instruction: The child performs the task, guided by covert self-speech.

These four steps represent only the bare bones of selfinstructional training. Six basic types of self-statements are modeled by the adult and rehearsed by the child (cf. Meichenbaum \& J. Goodman, 1971; Meichenbaum \& S. Goodman, 1979): (a) problem definition (What is it I have to do?); (b) focusing of attention (I have to concentrâte, think only about my work); (c) planning and response guidance (Be careful ... look at one at a time); (d) self-reinforcement (Good - I got it!); (e) self-evaluation (Am I following my plan ... did I look at each one?); and (f) coping and error-correcting options (That's ok ... even if I make an error I can back up and go slowly). These different types of statements are directed at alleviating deficits in comprehending the nature of the problem, producing task-relevant strategies and verbalizations, and using these strategies and verbalizations to directly and effectively mediate behavior (cf. Bem, 1970; Flavell et al., 1966; Reese, 1962).

In addition to these six types, self-statements can be divided into two levels (cf. Brown et al., 1981; Kendall, 1977; Meichenbaum, 1979a; Meichenbaum \& Asarnow, 1979): task-approach and task-specific. Task-approach statements refer to global metacognitive, cognitive, and behavioral strategies that are relevant across a variety of related tasks, as well as the task at hand. Task-approach statements can be aimed at components of the task and/or characteristics of the learner. An example of a task-approach statement aimed at the task (and of the problem definition type) is: What am I supposed to do here? . . . What is my first step? Task-approach statements can also be aimed at characteristics of the learner that may interfere with performance, such as impulsivity, external locus of control, or a helpless attitude. Examples include: I must remember to go slow and think first ... It's up to me how well I do... What's important is that I 
do $m y$ best. On the other hand, task-specific statements are relevant to the specific task at hand. An example of a task-specific statement (also of the problem definition type) is: I have to put this puzzle together . . . First, I have to turn all the pieces up.

All six types of self-statements can be developed at either the task-approach or task-specific level. Kendall and Finch (1979) reported that general, global taskapproach statements result in greater treatment effects and facilitate generalization. Lloyd (1980), however, suggested that task-specific strategies have a better chance of being successful on academic tasks. More research is needed on the differential effects of taskapproach and task-specific strategies and self-statements across varying tasks. A combination of the two levels may prove to be most effective, or a gradual transition from task-specific to task-approach statements may prove superior (Kendall, 1977; Meichenbaum, 1979a).

Self-instructional training also emphasizes the importance of the student playing an active, collaborative role in the design, implementation, and evaluation of training regimens (Meichenbaum, 1977). First, the student should help identify any negative, maladaptive, or ineffective cognitions and self-statements that occur. Then, the instructor and the learner should engage in what Meichenbaum terms a Socratic dialogue; the instructor might ask the student how he/she would do the task, then provide feedback and build on the student's advice. The purpose of the task, appropriate strategies, and how to effectively execute the strategy(ies) should be discussed. As training progresses, the instructor should gradually fade support so that the student is spontaneously generating and answering these questions on his/her own. The instructor might occasionally falter in the use of verbalizations and strategies and permit the student to catch the errors.

Self-instructional training should be long-term, occurring across tasks of graduated difficulty and in different settings. Reinforcing and coping statements should be modeled throughout training; all statements should be modeled with appropriate inflection and feeling and should be appropriate for the student's language level. Superficial imitation or mimicry should be discouraged. The child could be asked to re-word or abbreviate selfstatements as long as the meaning is preserved. Imagery might also be incorporated; the young, impulsive child might imagine a slow, careful turtle and say, "I will not go faster than a slow turtle." In short, self-instructional training "should not be viewed as regimented or austere but, rather, individually tailored and highly responsive to each child" (Meichenbaum, 1977, p. 98). Many investigators, however, have failed to follow the guidelines and parameters initially presented by Meichenbaum \& J. Goodman (1971) and later elaborated by Meichenbaum (1977).

\section{Problem-Solving Training}

Successful problem solving is an important factor in adjustment and mental health; problem solving increases coping skills, independence, and self-regulation, and helps to prevent future social and emotional problems (Craighead et al., 1978). Training in problem solving can be done in the classroom and has been effective in reducing behavior problems and aggression, controlling impulsivity, and increasing social interaction among shy, inhibited children (Craighead et al., 1978; Spivack \& Shure, 1974). Cognitive-behavioral approaches for training problem solving help meet the need for teaching exceptional students how to learn, may increase generalization, and may help prevent students from adopting strategies as blind rules (Meichenbaum, 1980b). Problem solving has been investigated from a number of perspectives, three of which are briefly discussed here.

Meichenbaum (1980b) noted that a number of general problem-solving strategies have been taught successfully via $\mathrm{CBM}$. These strategies include self-interrogation, self-checking, analyzing tasks and breaking problems into manageable steps and proceeding through these steps, and scanning strategies within one's abilities to find those that match the demands of a task. To master such strategies, the student must become more aware of his/her cognitive processes and abilities, and must learn to deautomatize the learning process. Then the student can learn when and how to employ problem-solving strategies and can develop a sense of efficacy in their use.

D'Zurilla and Goldfried (1971), after reviewing the literature, presented five general steps applicable to teaching problem solving:

1. General orientation: Help the student learn to recognize problems and to realize that problems can be dealt with in appropriate ways.

2. Problem definition: Operationally define the problem, consider the history of the problem, and identify antecedents and consequences controlling or related to the problem.

3. Generate alternatives: Brainstorming. All ideas should be accepted, and the student (and instructor) should think of as many solutions as possible, perhaps writing them down.

4. Decision making: Carefully examine the alternatives generated in step 3 in terms of their acceptability and short-term and long-range effectiveness. Then devise a plan for carrying out the selected alternative (s).

5. Implementation and evaluation: Implement the plan and carefully monitor it. If it does not solve the problem, start the sequence again.

Gordon (1974) has illustrated the use of these procedures in the classroom. 
Spivack, Platt, \& Shure (1976) identified five skills involved in social problem solving, which emerge and differ in significance at different ages: (a) an awareness that problems or potential problems may exist when humans interact; (b) the ability to generate alternative solutions to problems; (c) means-end thinking - being able to specify the steps necessary to carry out the solutions to problems; (d) understanding the consequences of behavior on self and others; and (e) causeeffect thinking - realizing that social interaction is a reciprocal, interactive process among those involved. Spivack and Shure (1974) found that children with behavior problems fail to consider possible consequences of their behavior and to generate alternative solutions and possibilities. They used approximately 30 lessons, in a game format; to help children with behavior problems learn to identify emotions, consider the feelings of others, generate alternative solutions to social problems, and evaluate cause-effect relationships. Training, whether by teachers or parents, resulted in significant and durable positive effects on social behavior with peers.

\section{Applications}

CBM has been applied to a host of social, emotional, and academic behaviors (Harris, 1981a). Target areas with exceptional students are given in Figure 1. Comprehensive reviews noting both the successes and failures of CBM are offered by Abikoff (1979), Craighead et al. (1978), and Meichenbaum (1979a).

Researchers have begun to study the efficacy of CBM procedures in classroom settings. Two of these studies are briefly presented here, to illustrate the use of CBM in the classroom.

\section{Study \#1}

Douglas et al. (1976) developed a training program for hyperactive children that has been termed the most comprehensive program to date for the treatment of

Figure 1

Applications of CBM

\section{Target Areas}

- Attentional deficits and impulsivity

- Reattribution and motivational training

- Problem solving

- Development of social skills and control of aggression and behavioral problems

- Memory

- Metacognition

- Training of intelligence

- Development of self-regulation and self-management skills

- Academic skills

Reading comprehension

\section{References}

Douglas, Parry, Marton, and Garson (1976)

Kendall and Finch $(1976 ; 1978 ; 1979)$

Keogh and Margolis (1976)

Messar (1970)

Canino (1981)

Diener and Dweck (1978)

Henker, Whelan, and Hinshaw (1980)

Thomas (1979)

McKinney and Haskins (1980)

Abikoff (1979)

Craighead, Wilcoxon-Craighead, and Meyers (1978)

Gresham (1981)

Kneedler (1980)

Brown (1974)

Campione and Brown (1977)

Brown, Campione, and Day (1981)

Loper (1980; in press)

Sabatino, Miller, and Schmidt (1981)

Sternberg (1981)

Karoly (1977)

Kneedler and Hallahan (in press)

Nelson (1977)

Pressley (1979)

Abikoff (1979)

Douglas, Parry, Marton, and Garson (1976)

Lloyd, Kosiewicz, and Hallahan (in press)

Graham (1982)

Kosiewicz, Hallahan, Lloyd, and Graves (1982) 
attentional problems (Craighead et al., 1978). Eighteen hyperactive boys (age 6 years, 1 month to 10 years, 11 months) with attentional and impulsivity problems participated in 24 one-hour training sessions over a threemonth period (two sessions per week). Parents and teachers observed and participated in these training sessions whenever possible. In addition, at least six consultation sessions with each child's teacher and 12 sessions with one or both parents were held. During these sessions, teachers and parents were taught cognitive and contingency management training techniques and ways to implement these techniques at home and school, as well as how to encourage and reinforce the child for using their new strategies in real-life situations. Cognitive modeling, self-verbalization, and self-reinforcement procedures were developed following self-instructional training guidelines presented by Meichenbaum and his colleagues.

These procedures were then used to teach general and specific strategies for coping effectively and independently "with cognitive problems and social situations in which care, attention, and organized planning are required; closely related to this goal was the need to help them achieve better inhibitory control" (Douglas et al., 1976, p. 393). Contingency management techniques were used only when a student was particularly unmanageable, and only minor emphasis was placed on limiting movement and decreasing distractors.

General, task-approach problem-solving strategies were taught, including: defining a problem and the various steps within it, generating and evaluating possible solutions before acting, self-checking and calmly correcting errors, staying with a problem until everything possible had been tried to solve it correctly, and self-reinforcement for work well done. The task-specific strategies taught included: searching, focusing, and attention deployment, planning ahead and thinking sequentially, organizing ideas and work materials, rehearsal and memory strategies, and strategies for cooperating with a peer on a task or game. These general and specific strategies were taught across a variety of cognitive tasks, academic assignments, and social situations. Students were trained in pairs part of the time. Training time on each activity was gradually extended as the sessions progressed.

Significant improvement was found on several measures, both immediately after training and at a threemonth follow-up. Areas of improvement included increased persistence, control of impulsive responding, coping with frustration, oral reading, and oral and listening comprehension. Little evidence for effects of training were found on the Bender-Gestalt Test, an arithmetic test, and on teacher ratings of hyperactive behaviors. Although training initially occurred outside of the classroom in this study, special educators could design and conduct similar training sessions within the classroom.

\section{Study \#2}

Hallahan, Marshall, and Lloyd (1981) taught three learning disabled boys to self-monitor their on-task behavior while participating in oral reading tasks. Selfmonitoring consisted of two components: self-assessment and self-recording. All training was conducted by the classroom teacher and an aide. A tape recorder placed behind the students emitted tones at random intervals. During the first phase of training, students were taught to ask themselves. "Was I paying attention?" at the sound of each tone. If students judged themselves to be on task (looking directly at the aide), they pressed a button on the wrist counters they wore; if not, they did nothing. The question, "Was I paying attention?" was written on the blackboard at the beginning of each lesson, as a cue. During initial training, the aide verbally corrected students when they made an incorrect recording.

After a three-week period, the cues for self-monitoring were gradually faded. For the next two weeks the wrist counters were not used. For the next three months the tape recorder was also removed, but the question, "Was I paying attention" was left on the blackboard. All three students made and sustained substantial gains in on-task behavior. This study illustrates a creative, relatively simple procedure that classroom teachers can easily use.

Space does not permit further examples. Interested readers are referred to Thomas and Pashley's (1982) classroom training on task persistence and attributions, as well as the articles listed previously on pages $10-11$.

\section{CONSTRUCTING AND IMPLEMENTING COGNITIVE-BEHAVIORAL INTERVENTIONS}

\section{Task Analysis}

The cognitive-behavioral approach requires more than an analysis of hierarchical component skills and the development of sequential learning activities designed to take the student through the steps in the task analysis. The psychological demands of the task and the sequential, organized cognitions that the student must engage in to perform adequately on the task must also be analyzed (Meichenbaum, 1976). The component cognitive strategies and the cognitive capacity required by each step in the task analysis must be identified (Brown, 1974; Meichenbaum \& Asarnow, 1979). As the cognitive processes required for performance become more numerous and complex, task difficulty increases and greater cognitive capacity is required (Carroll, 1981).

To determine the cognitions and strategies necessary for successful performance, the teacher or an "expert" 
(adult or student) might do the task, examining and reporting his/her strategies. The teacher might also observe and interview both those who do well and those who perform poorly, in order to speculate on what leads to poor performance. Cognitions involved in comprehension of the problem or task, the production of appropriate strategies, and the application and monitoring of these strategies should be considered. Both Case (1978) and Meichenbaum (1976) have detailed how this can be done.

Input and output modalities required by the task should be analyzed; training tasks should facilitate generalization of the strategies taught to problems requiring various modalities (Douglas et al., 1976). Materials used should be analyzed in terms of their logical structure, form, and content; they may provide cues and assistance for performance (Brown et al., 1981). The results of this cognitive-behavioral task analysis will be combined with results of the learner analysis in selecting CBM components and designing training procedures.

\section{Learner Analysis}

Analysis of the learner is a complex process, one that must go beyond data gathered from standardized and criterion-referenced tests. Characteristics and predilections that the learner brings to the task may include: age, cognitive capacity and capabilities, language development, attributions and beliefs, motivational level, learning style, internal dialogue, initial knowledge state, spontaneously produced strategies, and responses to behavioral antecedents, consequences, contingencies, and medication (when appropriate). Each of these characteristics, and any others relevant to the goal of training and the task(s) involved, should be carefully considered.

Task and training requirements must be compatible with the learner's cognitive capacity, chronological age, and mental age. Cognitive capacity influences the form, content, and rate of training (Meichenbaum 1980b). Kendall (1977) noted that slow learners may need careful pretraining in the use of self-instructions (e.g., rote memorization of several self-statements), on component task skills (e.g., holding a pencil), and on attending to and copying a model. Young students and those with severe learning problems may be incapable of dealing with more than a few items of information at one time, because of limited memory or information processing abilities. Too, they may produce strategies that are reasonable but oversimplified (Case, 1978). Overt verbalizations, concrete, externally based training, and frequent, salient reinforcement may be necessary and more effective with younger children and those with greater deficits (Henker et al., 1980; Loper, 1980).

Brown et al. (1981) concluded that the more severe the learner's problem is, the more explicit the training must be; procedures must be developed to help the learner integrate general training, self-management training, and strategy training. Older, more intelligent students may respond readily to simpler procedures such as modeling, cognitive modeling, or instructions (Wagner, cited in Craighead et al., 1978).

Language development is another variable to be examined (Kendall, 1977; Keogh \& Glover, 1980). The learner's receptive and expressive vocabulary, language style, and idiosyncratic preferences should be monitored. Self-statements and instructions used in CBM can then be matched to the individual's verbal style and language ability level. A language sample can also provide a measure of cognitive development (Maier, 1980).

An integral part of CBM design is assessment and understanding of the learner's cognitions. The student's attributions, belief systems, and expectancies can all interact with training components and approaches. $\mathrm{Al}$ though modifying an individual's belief system is not easy (Mahoney, 1977b), CBM with exceptional students must often contain components aimed at modifying maladaptive, inappropriate, or ineffective cognitions. Holland (1982) identified motivation, persistence, responsibility, and structure as four elements crucial to learning and noted that students high in these characteristics perform more effectively and require significantly less structure. CBM procedures should be aimed at positively affecting these characteristics. And, since interventions create attributions (Craighead et al., 1978; Henker et al., 1980), the student's feelings about both the training program and his/her performance should be carefully monitored and assessed.

Cognitive assessment is not an easy task and is therefore often neglected (Sternberg, 1981). Cognitive assessment must focus on the dynamic processes involved in thinking and learning. Intraindividual differences and the interaction of the learner with materials and information to be learned should be examined (Sabatino et al., 1981). Though a great deal of interest and growth is evident in this area, relatively few cognitive or cognitivebehavioral instruments exist. Also lacking is readily available information on the cognitive strategies effective with academic and learning tasks among students of differing ages and abilities (Thomas \& Pashley, 1982).

Various procedures have been recommended for assessing cognitions. Interviews, post-performance questionnaires, thought listing, think aloud, and other verbal report measures may provide valuable information on both the presence of maladaptive cognitions and the absence of appropriate, adaptive cognitions and strategies (Case, 1978; Meichenbaum, 1979a). Caution should be exercised in tapping self-reports of cognitions, however, because the reliability and validity of such selfreports are often unknown, a student may have difficulty communicating cognitions verbally, and self-awareness 
is a skill that must be acquired (Meichenbaum, 1979a; O'Leary, 1980).

Observation and daily record keeping on responses to questions, approaches, and probes may also be helpful (Reid \& Hresko, 1980). Since the way in which questions are asked may affect the answers, listening to spontaneous conversations and informal, open-ended discussions may help provide objective information (Henker et al., 1980). Further information on the presence or absence of skills and cognitions may be gained by manipulating characteristics of the task (modality or presentation, rate of stimulus presentation, support available, and so on) and by creating modified versions of the task that help to identify the student's task approach (Case, 1978; Meichenbaum, 1976).

Establishing the learner's initial knowledge state is important, including both the spontaneous strategies the learner produces in the learning situation and the strategies the learner is capable of using but does not produce. This information can help to determine cognitive capacity and to establish what the learner is.doing or failing to do that interferes with performance (Meichenbaum, 1976). Knowledge of these things is critical in setting the goal of training, choosing training tasks, and establishing the sequence of learning activities that lead to the established goal. The learner's metacognitive skills must also be assessed, including self-awareness and the learner's ability to assess a situation, identify available, relevant strategies, choose among alternatives, develop a plan, monitor performance, and modify cognitive activities as necessary (Loper, 1980; Henker et al., 1980). Training must often be aimed at deficits in metacognition.

Lastly, relevant aspects of the learner's cognitive and learning style should be considered, and task demands altered if the student's learning style, informationprocessing pattern, or cognitive style is not compatible with the task (Holland, 1982). For example, fielddependent students can learn more rapidly when cue salience and structure are increased (Holland, 1982). Students who are both field-dependent and impulsive often have severe learning problems and require special consideration (Keogh \& McG. Donlon, 1972). The student's locus of control, whether the problem is seen as internally or externally controlled, may also interact with training and task requirements (Henker et al., 1980). Holland (1982) has discussed elements of cognitive and learning styles.

If task and training requirements are not matched to the learner's characteristics and predilections, problems can occur. Students may learn to use a strategy and yet show no improvement in performance. For example, training an impulsive child to delay responding, adopt a more reflexive style, and stay on-task will have little effect if the child does not know what to do with the time gained. The child must also be taught to utilize cognitive strategies appropriate to the task, such as effective scanning, matching to standard, reviewing and checking solutions, and so on (Craighead et al., 1978).

Moreover, if current abilities are not well understood, the learner may be taught a strategy less efficient or no better than the one he/she is already using (Loper, 1980), or one that is beyond his/her cognitive-developmental abilities. Students with a helpless attitude, feelings of anger or dislike for learning, a low self-concept, negative expectancies, a low need for achievement, or a low motivational level may exert little or no effort to learn new skills or to use the skills they do learn to improve performance. Other students simply may not believe that their new skills are more efficient or effective than their current behaviors.

\section{Development and Implementation}

In conjunction with a careful, thorough analysis of task and learner, operationally defined goals of training are established. Then the teacher (or researcher) selects CBM components and procedures appropriate to the task, learner, and goals. Simple procedures, such as explaining a strategy or providing a model, may be all that is necessary when the task is simple or the learner's problems are relatively minor. As the goals of training become more involved (e.g., development of effective problem solving and metacognitive skills) and the learner's deficits more significant, training becomes more complex, requiring multiple training tasks, components, and stages.

In designing the $\mathrm{CBM}$ intervention, the teacher must keep in mind the purpose of training and tailor learning activities to the desired outcomes (Brown et al., 1981). Is the purpose to learn a specific skill, to teach the use of a certain strategy(ies), or both? Training should focus on the operationally defined goals and not on some abstract dimension or presumed underlying deficit (Craighead et al., 1978; Meichenbaum \& Asarnow, 1979).

The teacher must determine whether self-instructions, imagery, modeling, shaping, successive approximations, contingencies such as reinforcement or response-cost, and so on will be used. Task-approach and task-specific strategies must be identified and, if appropriate, corresponding verbalizations developed. Strategy instructions must be well formulated and appropriate for learners' cognitive and developmental levels. Learners should be as actively involved as possible in the design, implementation, and evaluation of CBM training.

Once the CBM regimen is developed, training is initiated. Training can be facilitated if the student is first made aware of any negative or ineffective self-statements and strategies he/she is producing, if the advantages of the strategy(ies) to be taught are made clear, and if the student desires the training (Case, 1978; Meichenbaum, 
1976). A favorable relationship with the student and an enthusiastic attitude on the part of the trainer are also important (Kendall, 1977).

If multiple components and procedures are to be used in training, it may be helpful to begin on tasks at which the learner is somewhat proficient, gradually introducing new components and procedures. One should begin with a simple set of self-statements, self-instructions, or selfcontrolled consequences and gradually work toward more complex sets. Task difficulty and length of training sessions should be gradually increased. Sufficient practice should be provided, using interesting and varied materials. Learner management and control of strategies should be emphasized. External control, prompts, and cues should be gradually decreased. The student should be allowed to abbreviate verbalizations and steps after demonstrating mastery of a skill. The effects of training should be monitored, and revised as necessary.

\section{Overt Verbalizations}

Self-instructions, at first overt and later covert, have generally been found to be an effective, important part of training (Craighead et al., 1978; Douglas et al., 1976; Kendall, 1977; Meichenbaum \& Asarnow, 1979; Pressley, 1979). Researchers who have employed overt verbalizations as a part of CBM training have made several suggestions. Meichenbaum (1977) noted that students may respond more favorably when they are asked to "think aloud" rather than to "talk out loud to yourself."

Optimal use of overt and covert verbalizations should be considered, as overt verbalizations may interfere with behaviors that are timed, require reflexive reactions, or involve complex processing (Harris, 1981a; Meichenbaum \& J. Goodman, 1969). For example, Robin, Armel, and O'Leary (1975) found overt verbalizations cumbersome and difficult to shape while teaching a group of naive kindergartners to print. Kosiewicz et al. (1982) reported no difficulties with self-instructions used to improve one student's cursive writing. Douglas et al. (1976) noted that problems with overt verbalizations are most likely to occur when self-verbalization is taught in a mechanical, rote-learning manner. Problems can be avoided if the student is involved in the development of verbalizations and encouraged to verbalize strategies in his/her own words. If students resist the use of overt verbalizations or find it embarrassing, they might be allowed to practice in isolation, whisper, or speak into a microphone. A tape recorder might also be used to monitor the precision and consistency of the self-instructions modeled by the trainer and copied by the student.

\section{Correspondence between Saying and Doing}

When verbalizations are used, correspondence between saying and doing should be carefully monitored. Merely saying the right things or a doing-saying sequence does not have as significant an effect on behavior (Craighead et al., 1978; Kendall, 1977). Some time may have to be spent in shaping and developing correspondence between verbalizations and the behaviors they are to control (Meichenbaum, 1980b).

\section{Modeling}

When a live model is used in CBM training, this model should be carefully selected. To be effective, the model must be viewed favorably (i.e., seen as competent, attractive, rated high on a sociometric scale, and so on) and have a positive relationship with the student (Bandura, 1977a; Craighead et al., 1978). Teachers, parents, paraprofessionals, and peers can be effective models. The model should be enthusiastic and use self-statements with appropriate phrasing and inflection. In some cases, allowing the target student to serve as a model for another student can improve performance (Pressley, 1979).

In addition, modeling of self-instructions and selfregulation can be done on an impromptu basis, during games, discussions, instruction, and everyday occurrences. Although live models are often preferable and more effective (Kendall, 1977; Ledwidge, 1978), other alternatives have been used successfully. Examples include a permanent model or written list of steps and statements, tape-recorded statements, the combination of a written model and tape-recorded statements, videotapes, and cartoons or drawings (cf. Harris, 1980, 1981a, 1982; Lloyd, 1980; Meichenbaum, 1977).

\section{Individual vs. Group Training}

Although individual training is frequently preferable and more efficient, it may not be practical for all problems or classroom settings. While CBM training can be conducted effectively in small groups, special considerations are warranted. Developing self-instructions compatible with several students' individual styles may pose a problem (Kendall, 1977). To handle this problem, the teacher might model a statement and then encourage each student to express the same idea in his/her own words. An aide or peer may be needed to help monitor consistent and proficient usage of self-statements. Individual students should be allowed to progress through training activities at their own rate. Even within a group setting, training should be as individualized as possible.

\section{Durable and Generalizable Results}

If the results of CBM training are to be significant, they must be durable and generalizable to new tasks, settings, and conditions. Brief, short-term interventions should not be expected to show long-term, generalizable 
effects. Durability appears easier to obtain than generalization, although reports of generalization are increasing as CBM regimens become more sophisticated in design and implementation (cf. Brown et al., 1981; Douglas et al., 1976; Hollon \& Kendall, 1979; Meichenbaum, 1979a; Seabaugh \& Schumaker, 1981).

The ability to generalize may be related to age, readiness, and metacognitive maturity, as generalization requires changes in metacognitive development and abilities (Loper, 1980; Meichenbaum \& Asarnow, 1979). Young children may be more likely to maintain and generalize skills when the training and generalization tasks are concrete and familiar. Blankenship \& Baumgartner (1982) noted that differentiating between students who can't generalize and those who can but won't may be necessary. The former may require more intensive instruction, while contingent reinforcement may prove effective with the latter.

Although the "train and hope" approach to obtaining generalization may be the most frequent method used, maintenance and generalization should be planned and programmed (Stokes \& Baer, 1977). The following suggestions for enhancing durability and generalization have been offered by various researchers (cf. Borkowski \& Cavanaugh, 1979; Deshler et al., 1981; Douglas et al., 1976; Kendall, 1977; Kendall \& Finch, 1979; Meichenbaum \& Asarnow, 1979; Stokes \& Baer, 1977):

1. Develop training procedures and behaviors that can be maintained by natural contingencies after transfer to a new environment or situation.

2. Provide training that is prolonged and in depth, and conducted by several individuals across a variety of tasks, materials, modalities, settings, and conditions.

3. Make sure that stimuli common to the generalization setting(s) are also present in the training setting.

4. If distractors will be present in the generalization setting, include in the training gradual innoculation against distractors and coping strategies for handling distraction.

5. Tell students to generalize, and reinforce instances of generalization.

6. In training, emphasize the development of metacognitive, self-regulatory skills.

7. Gradually fade cues and prompts during training, to facilitate transfer of control to the student.

8. Make use of delayed and intermittent reinforcement during training, to strengthen learned skills and behaviors. Durability is necessary but not sufficient for generalization.

9. Require similar (but not necessarily identical) cognitions and skills in the training and generalization tasks.
10. Gradually adapt training materials and setting to the terminal goal. Training a child to cope with frustration on a maze task is not likely to improve aggressive tendencies with peers without intermediate steps.

11. Provide feedback about the purpose and usefulness of the strategy(ies) taught, as well as feedback on the learner's performance.

12. Gradually increase the demand for mental involvement in the training tasks.

13. Actively involve the student in the development of training and the acquisition of new strategies and skills.

14. Emphasize consistency and precision in strategy use during the initial phase of strategy instruction, then train loosely.

15. Facilitate generalization by attributing observed changes to the student's own efforts.

\section{Caveats}

CBM is not a panacea or a remedy for all the problems facing exceptional students and their teachers. Academic and learning proficiency represent a composite of many skills. As Sabatino et al. (1981) noted, no one intervention can affect all aspects of behavior and performance. Knowledge of CBM components and procedures allows teachers to expand the scope of their intervention and classroom approaches and provides guidance in the use of eclectic interventions. CBM should be used when it meets the learner's needs and characteristics, is appropriate for the problem, and is likely to be more effective than alternative interventions. For example, Keogh and Glover (1980) reported that CBM has improved problem-solving performance, decreased impulsiveness, and increased attention to various tasks, but has not been as effective as medication in reducing activity level, or as effective as behavior modification in increasing specific on-task behavior during academic tasks.

Direct training and modification of task demands may be as effective as CBM and more cost-effective with some problems (Craighead et al., 1978; McKinney \& Haskins, 1980). Global cognitions and behaviors (e.g., aggression) or those that are well instated may be particularly difficult to modify and require extended intervention. In addition, cognitive changes may take some time to result in improved academic performance or behavioral changes (Abikoff, 1979; Craighead et al., 1978).

\section{Research and Advances Needed}

Design flaws and simplistic, naive conceptualization and construction of CBM interventions has characterized many research studies (Meichenbaum, 1979a, 1979b; 
Meichenbaum \& Asarnow, 1979; Sabatino et al., 1981). CBM procedures and research design must be carefully evaluated when drawing conclusions about the effectiveness of CBM regimens. Well designed, carefully formulated studies have proven the viability and superiority of cognitive-behavioral interventions across a range of populations and problems (Hollon \& Kendall, 1979). Nevertheless, a great many questions remain to be answered.

One, further substantiation of durable and generalizable effects is needed. Two, researchers must turn their attention to identifying the necessary and sufficient components for lasting and generalizable results among different types of learners. In group studies in which CBM does not result in significant long-term effects for the majority of subjects, lasting effects may occur for some individuals (cf. Harris, 1980). Researchers should investigate predictors of sustained effects among these individuals. Three, more data are needed on the use of CBM in classroom settings, on the relationship between developmental level and treatment, on matching treatment to the learner, and on the relative and combined effects of specific skill training and training general, metacognitive skills (Abikoff, 1979; Craighead et al., 1978; Meichenbaum, 1979b; O'Leary, 1980). Four, acceptable, reliable measures of cognitive processes have to be developed to assist in the design and evaluation of CBM regimens. Finally, we need to know more about the causal links between cognitive phenomena and behaviors and what factors influence the development, maintenance, or change of cognitions (Mahoney, 1977a).

In summary, CBM must remain open to diligent and critical examination to help assure proper application and successful results. Caution should be taken to avoid inappropriate proliferation of CBM techniques and the use of CBM merely because it represents a current fad (Kendall, 1977).

\section{The Teacher}

The use of cognitive-behavioral interventions creates many demands on classroom teachers. Considerable time is necessary for the analyses, planning, and implementation procedures required for success. CBM requires teachers to keep up with a dynamic area and be diversified in skills and knowledge. To paraphrase Mahoney (1977a), the teacher must be aware of students' physical, cognitive, and social environment, a good listener, an accurate observer, and an effective problem solver. The teacher has to adopt a metacognitive perspective and develop an understanding of the demands of learning (Brown et al., 1981). Tasks and activities that require students to use metacognitive skills must be developed and opportunities for the use of metacognitive skills identified (Meichenbaum \& Asarnow, 1979).
The teacher has to establish the credibility of CBM in the classroom and obtain student cooperation and support (Meichenbaum, 1979a). An academic focus must be maintained, and CBM procedures should not be used to the point of boredom, fatigue, or carelessness (cf. Tobias, 1982). The natural development of behavioral regulation is a slow process keyed to developmental stages. The teacher should act as a model of selfregulation, problem solving, and coping with difficulties and failures. The success of CBM depends on the teacher's understanding of all of these points, and not on the casual "throwing in" of verbalizations with existing instructional procedures.

\section{CONCLUSION}

Cognitive-behavioral interventions appear to be a promising approach with exceptional students. Special educators should carefully monitor research findings, advances, and new contributors in this area. Though further work is needed to establish the parameters of $\mathrm{CBM}$ interventions and their relationships to desired effects, the selective, empirically based combination of principles and procedures from diverse areas offers a viable alternative for dealing with the problems of exceptional students.

\section{REFERENCES}

Abikoff, H. Cognitive training interventions in children: Review of a new approach. Journal of Learning Disabilities, 1979, 12, 65-77.

Anderson, R. Control of student mediating processes during verbal learning and instruction. Review of Educational Research, 1970, 40, 349-369.

Bandura, A. Social learning theory. Englewood Cliffs, NJ: PrenticeHall, 1977. (a)

Bandura, A. Self-efficacy: Toward a unifying theory of behavioral change. Psychological Review, 1977, 84, 191-215. (b)

Bandura, A. The self system in reciprocal determinism. American Psychologist, 1978, 33, 344-358.

Bem, S. The role of comprehension in children's problem solving. Developmental Psychology, 1970, 2, 351-358.

Blankenship, C. S., \& Baumgartner, M. D. Programming generalization of computational skills. Learning Disability Quarterly, 1982, $5,152-162$.

Borkowski, J. G., \& Cavanaugh, J. C. Maintenance and generalization of skills and strategies by the retarded. In N. R. Ellis (Ed.), Handbook of mental deficiency: Psychological theory and research (2nd ed.). Hillsdale, NJ: Erlbaum, 1979.

Brown, A. L. The role of strategic behavior in retardate memory. In N. R. Ellis (Ed.), International review of research in mental retardation (Vol. 7). New York: Academic Press, 1974.

Brown, A. L., Campione, J. C., \& Day, J. D. Learning to learn: On training students to learn from text. Educational Researcher, 1981, $10,14-21$.

Camp, B. W. Verbal mediation in young aggressive boys. Journal of Abnormal Psychology, 1977, 86, 145-153.

Camp, B. W., Blom, G. E., Hebert, F., \& Van Doorninck, W. J.'Think aloud: A program for developing self-control in young aggressive boys. Journal of Abnormal Child Psychology, 1977, 5, 157-169.

Campione, J. C., \& Brown, A. L. Memory and metamemory development in educable retarded children. In R. V. Kail, Jr., \& J. 
W. Hagen (Eds.), Perspectives on the development of memory and cognition. Hillsdale, NJ: Erlbaum, 1977.

Canino, F. J. Learned-helplessness theory: Implications for research in learning disabilities. Journal of Special Education, 1981, 15, $471-484$.

Carroll, J. B. Ability and task difficulty in cognitive psychology. Educational Researcher, 1981, 10, 11-21.

Case, R. A. A developmentally based theory and technology of instruction. Review of Educational Research, 1978, 48, 439-463.

Craighead, W. E., Wilcoxon-Craighead, L., \& Meyers, A. W. New directions in behavior modification with children. In M. Hersen, R. M. Eisler, \& P. M. Miller (Eds.), Progress in behavior modification (Vol. 6). New York: Academic Press, 1978.

Cullinan, D., Lloyd, J., \& Epstein, M. Strategy training: A structured approach to arithmetic instruction. Exceptional Education Quarterly, 1980, 1, 41-49.

Denney, D. R. Modification of children's information processing behavior through learning. Child Study Monographs, 1973, I, $1-22$.

Denney, D. R. The effects of exemplary and cognitive models and self-rehearsal on children's interrogative strategies. Journal of Experimental Child Psychology, 1975, 19, 476-488.

Denney, N. W., \& Turner, M. C. Facilitating cognitive performance in children: A comparison of strategy modeling and strategy modeling with overt self-verbalization. Journal of Experimental Child Psychology, 1979, 28, 119-131.

Deshler, D. D., Alley, G. R., Warner, M. M., \& Schumaker, J. B. Instructional practices for promoting skill acquisition and generalization in severely learning disabled adolescents. Learning Disability Quarterly, 1981, 4, 415-421.

Diener, C. I., \& Dweck, C. S. An analysis of learned helplessness: Continuous changes in performance, strategy, and achievement cognitions following failure. Journal of Personality \& Social Psychology, 1978, 36, 451-462.

Douglas, V. I. Perceptual and cognitive factors as determinants of learning disabilities: A review paper with special emphasis on attentional factors. In R. M. Knights \& D. J. Bakker (Eds.), Neuropsychology of learning disorders: Theoretical approaches. Baltimore: University Park Press, 1975.

Douglas, V. I., Parry, P., Marton, P., \& Garson, C. Assessment of a cognitive training program for hyperactive children. Journal of Abnormal Child Psychology, 1976, 4, 389-410.

D'Zurilla, T. J., \& Goldfried, M. R. Problem solving and behavior modification. Journal of Abnormal Psychology, 1971, 78, 107-126.

Ellis, A. Reason and emotion in psychotherapy. New York: Lyle Stuart, 1963.

Finch, A. J., Jr., \& Spirito, A. Use of cognitive training to change cognitive processes. Exceptional Education Quarterly, 1980, 1, 31-39.

Flavell, J. H., Beach, D. R., \& Chinsky, J. M. Spontaneous verbal rehearsal in a memory task as a function of age. Child Development, 1966, 37, 283-299.

Gordon, T. Teacher effectiveness training. New York: Peter W. Wyden, 1974.

Graham, S. The effects of cognitive and behavioral procedures on the handwriting performance of $L D$ students. Manuscript submitted for publication, 1982.

Gresham, F. Social skills training with handicapped children: A review. Review of Educational Research, 1981, 51, 139-176.

Hallahan, D. P., Gajar, A., Cohen, S., \& Tarver, S. Selective attention and locus of control in learning disabled and normal children. Journal of Learning Disabilities, 1978, 11, 47-52.

Hallahan, D. P., Marshall, K. J., \& Lloyd, J. W. Self-recording during group instruction: Effects on attention to task. Learning Disability Quarterly, 1981, 4, 407-413.

Harris, K. R. The sustained effects of cognitive modification and informed teachers on children's communication apprehension. Communication Quarterly, 1980, 28, 47-56.

Harris, K. R. Self-speech, language, and cognitive training: A review of theory and practice. Paper presented at the meeting of the
International Communication Association, Minneapolis, May 1981: (a)

Harris, K. R. The effects of cognitive training on self-speech and task performance during problem solving among learning disabled and normally achieving children. Unpublished doctoral dissertation, Auburn University, 1981. (b)

Harris, K. R. The effects of cognitive training on private speech and task performance during problem solving among learning disabled and normally achieving children. Paper presented at the meeting of the American Educational Research Association, New York, March 1982.

Harris, K. R., \& Brown, R. Cognitive-behavior modification and informed teacher treatments for shy children. Journal of Experimental Education, 1982, 50, 137-143.

Havertape, J. F., \& Kass, C. E. Examination of problem solving in learning disabled adolescents through verbalized self-instructions. Learning Disability Quarterly, 1978, 1, 94-100.

Henker, B., Whalen, C. K., \& Hinshaw, S. P. The attributional contexts of cognitive intervention strategies. Exceptional Education Quarterly, 1980, 1, 17-30.

Holland, R. P. Learner characteristics and learner performance: Implications for instructional placement decisions. Journal of Special Education, 1982, 16, 7-20.

Hollon, S. D., \& Kendall, P. C. Cognitive-behavioral interventions: Theory and procedure. In P. C. Kendall \& S. D. Hollon (Eds.), Cognitive-behavioral interventions: Theory, research, and procedures. New York: Academic Press, 1979.

Kanfer, F. H., \& Karoly, P. Self-control: A behavioristic excursion into the lion's den. Behavior Therapy, 1972, 3, 398-416.

Kanfer, F. H., \& Phillips, J. S. Learning foundations of behavior therapy. New York: Wiley, 1970.

Karoly, P. Behavioral self-management in children: Concepts, methods, issues and directions. In M. Hersen, R. M. Eisler, \& P. M. Miller (Eds.), Progress in behavior modification (Vol. 5). New York: Academic Press, 1977.

Keeney, T. J., Cannizzo, S. R., \& Flavell, J. H. Spontaneous and induced verbal rehearsal in a recall task. Child Development, 1967, 38, 953-966.

Kendall, P. C. On the efficacious use of verbal self-instructional procedures with children. Cognitive Therapy \& Research, 1977, 4, 331-341.

Kendall, P. C., \& Finch, A. J. A cognitive-behavioral treatment for impulse control: A case study. Journal of Consulting \& Clinical Psychology, 1976, 44, 852-857.

Kendall, P. C., \& Finch, A. J. A cognitive-behavioral treatment for impulsivity: A group comparison study. Journal of Consulting \& Clinical Psychology, 1978, 46, 110-118.

Kendall, P. C., \& Finch, A. J. Developing nonimpulsive behavior in children: Cognitive-behavioral strategies for self-control. In P. C. Kendall \& S. D. Hollon (Eds.), Cognitive-behavioral interventions: Theory, research and procedures. New York: Academic Press, 1979.

Kendall, P. C., \& Hollon, S. D. Cognitive-behavioral interventions: Overview and current status. In P. C. Kendall \& S. D. Hollon (Eds.), Cognitive-behavioral interventions: Theory, research, and procedures. New York: Acacemic Press, 1979.

Kendler, J. S., Kendler, H. H., \& Wells; D. Reversal and nonreversal shifts in nursery school children. Journal of Comparative \& Physiological Psychology, 1960, 53, 83-88.

Keogh, B. K., \& Glover, A. T. The generality and durability of cognitive training effects. Exceptional Education Quarterly, 1980, $1,75-82$.

Keogh, B. K., \& Margolis, J. A component analysis of attentional problems of educationally handicapped boys. Journal of Abnormal Child Psychology, 1976, 4, 349-359.

Keogh, B. K., \& McG. Donlon, G. Field dependence, impulsivity, and learning disabilities. Journal of Learning Disabilities, 1972, 5 , 331-335.

Kneedler, R. D. The use of cognitive training to change social behaviors. Exceptional Education Quarterly, 1980, 1, 65-73. 
Kneedler, R. D., \& Hallahan, D. P. Self-monitoring of on-task behavior with learning disabled children: Current studies and directions. Exceptional Education Quarterly, in press.

Kosiewicz, M. M., Hallahan, D. E., Lloyd, J., \& Graves, A. W. Effects of self-instruction and self-correction procedures on handwriting performance. Learning Disability Quarterly, 1982, 5, $71-78$.

Kuenne, M. K. Experimental investigation of the relation of language to transposition behavior in young children. Journal of Experimental Psychology, 1946, 36, 471-490.

Ledwidge, B. Cognitive behavior modification: A step in the wrong direction? Psychological Bulletin, 1978, 85, 353-375.

Lloyd, J. Academic instruction and cognitive behavior modification: The need for attack strategy training. Exceptional Education Quarterly, 1980, I, 53-63.

Lloyd, J., Kosiewicz, M. M., \& Hallahan, D. P. Reading comprehension: Cognitive training contributions. School Psychology Review, in press.

Loper, A. B. Metacognitive development: Implications for cognitive training. Exceptional Education Quarterly, 1980, 1, 1-8.

Loper, A. B. Metacognitive training to correct academic deficiency. Topics in Learning \& Learning Disabilities, in press.

Luria, A. R. Verbal regulation of behavior. In M. A. B. Brazier (Ed.), The central nervous system and behavior. New York: Josiah Macy, Jr., Foundation, 1960.

Luria, A. R. The role of speech in the regulation of normal and abnormal behavior. (J. Tizard, trans.). New York: Liveright, 1961. (a)

Luria, A. R. The genesis of voluntary behavior. In N. O'Connor (Ed.), Recent Soviet psychology. New York: Liveright, 1961. (b)

Maccoby, E. E. Developmental psychology. Annual Review of Psychology, 1964, 15, 203-250.

Mahoney, M. J. Reflections on the cognitive learning trend in psychotherapy, American Psychologist, 1977, 32, 5-13. (a)

Mahoney, M. J. Cognitive therapy and research: A question of questions. Cognitive Therapy \& Research, 1977, 1, 5-16. (b)

Mahoney, M. J., \& Thoresen, C. E. Self-control: Power to the person. Monterey, CA: Brooks/Cole, 1974.

Maier, A. The effect of focusing on the cognitive processes of learning disabled children. Journal of Learning Disabilities, 1980, 13, 34-38.

McKinney, J. D., \& Haskins, R. Cognitive training and the development of problem-solving strategies. Exceptional Education Quarterly, 1980, 1, 41-51.

Meichenbaum, D. Cognitive factors as determinants of learning disabilities: A cognitive-functional approach. In R. M. Knights \& D. J. Bakker (Eds.), The neuropsychology of learning disorders: Theoretical approaches. Baltimore: University Park Press, 1976.

Meichenbaum, D. Cognitive behavior modification: An integrative approach. New York: Plenum Press, 1977.

Meichenbaum, D. Cognitive-behavior modification newsletter (No. 4). Waterloo, Ontario: University of Waterloo, 1979. (a)

Meichenbaum, D. Cognitive behavior modification: The need for a fairer assessment. Cognitive Therapy \& Research, 1979, 3, 127-132. (b)

Meichenbaum, D. Cognitive behavior modification with exceptional children: A promise yet unfulfilled. Exceptional Education Quarterly, 1980, l, 83-88. (a)

Meichenbaum, D. Teaching thinking: A cognitive-behavioural perspective. Paper presented at the NIE-LRDC Conference on Thinking and Learning Skills, Pittsburgh, October 1980. (b)

Meichenbaum, D., \& Asarnow, J. Cognitive-behavioral modification and metacognitive development: Implications for the classroom. In P. C. Kendall \& S. D. Hollon (Eds.), Cognitive-behavioral interventions: Theory, research, and procedures. New York: Academic Press, 1979.

Meichenbaum, D., \& Goodman, J. The developmental control of operant motor responding by verbal operants. Journal of Experimental Child Psychology, 1969, 7, 553-565.

Meichenbaum, D., \& Goodman, J. Training impulsive children to talk to themselves: A means of developing self-control. Journal of Abnormal Psychology, 1971, 77, 115-126.
Meichenbaum, D., \& Goodman, S. Clinical use of private speech and critical questions about its study in natural settings. In G. Zivin (Ed.), The development of self-regulation through private speech. New York: Wiley \& Sons, 1979.

Messar, S. B. Reflection-impulsivity: Stability and school failure. Journal of Educational Psychology, 1970, 61, 487-490.

Nelson, R. O. Assessment and therapeutic functions of self-monitoring. In M. Hersen, R. M. Eisler, \& P. M. Miller (Eds.), Progress in behavior modification (Vol. 5). New York: Academic Press, 1977.

O'Leary, S. G. A response to cognitive training. Exceptional Education Quarterly, 1980, 1, 89-94.

Pressley, M. Increasing children's self-control through cognitive interventions. Review of Educational Research, 1979, 49, 319-370.

Reese, H. W. Verbal mediation as a function of age level. Psychological Bulletin, 1962, 59, 501-509.

Reid, D. K., \& Hresko, W. P. Thinking about thinking about it in that way: Test data and instruction. Exceptional Education Quarterly, 1980, 1, 47-58.

Robin, A., Armel, S., \& O'Leary, K. D. The effects of self-instruction on writing deficiencies. Behavior Therapy, 1975, 6, 178-187.

Robin, S., Schneider, M., \& Dolnick, M. The turtle technique: An extended case study of self-control in the classroom. In K. D. O'Leary \& S. G. O'Leary (Eds.), Classroom management: The successful use of behavior modification (2nd ed.). New York: Pergamon, 1977.

Sabatino, D. A., Miller, P. F., \& Schmidt, C. Can intelligence be altered through cognitive training? Journal of Special Education, $1981,15,125-144$.

Schneider, M. Turtle technique in the classroom. Teaching Exceptional Children, 1974, 7, 22-24.

Seabaugh, G. O., \& Schumaker, J. B. The effects of self-regulation training on the academic productivity of $L D$ and NLD adolescents (Research Report No. 37). Lawrence, KS: Institute for Research in Learning Disabilities, University of Kansas, April 1981.

Spivack, G., Platt, J. J., \& Shure, M. B. The problem-solving approach to adjustment. San Francisco: Jossey-Bass, 1976.

Spivack, G., \& Shure, M. B. Social adjustment of young children: $A$ cognitive approach to solving real-life problems. San Francisco: Jossey-Bass, 1974.

Sternberg, R. J. Cognitive-behavioral approaches to the training of intelligence in the retarded. Journal of Special Education, 1981, 15, 165-183.

Stevens, R., \& Rosenshine, B. Advances in research on teaching. Exceptional Education Quarterly, 1981, 2, 1-9.

Stokes, T., \& Baer, D. An implicit technology of generalization. Journal of Applied Behavior Analysis, 1977, 10, 349-367.

Thomas, A. Learned helplessness and expectancy factors: Implications for research in learning disabilities. Review of Educational Research, 1979, 49, 208-221.

Thomas, A., \& Pashley, B. Effects of classroom training on LD students' task persistence and attributions. Learning Disability Quarterly, 1982, 5, 133-144.

Thoresen, C. E. Behavioral means and humanistic ends. In M. J. Mahoney \& C. E. Thoresen (Eds.), Self-control: Power to the person. Monterey, CA: Brooks/Cole, 1974.

Tobias, S. When do instructional methods make a difference? Educational Researcher, 1982, 11, 4-9.

Vygotsky, L. S. Thought and language. (E. Hanfmann \& G. Vakar, Eds. and trans.). Cambridge, MA: MIT Press, 1962. (originally published, 1934)

Wertsch, J. V. From social interaction to higher psychological processes, a clarification and application of Vygotsky's theory. Human Development, 1979, 22, 1-22. (a)

Wertsch, J. V. The regulation of human action and the given-new structure of private speech. In G. Zivin (Ed.), The development of self-regulation through private speech. New York: Wiley \& Sons, 1979. (b)

Zivin, G. (Ed.). The development of self-regulation through private speech. New York: Wiley \& Sons, 1979. 